\title{
A CONCEPÇÃO DE DEFICIÊNCIA INTELECTUAL AO LONGO DA HISTÓRIA
}

\section{THE CONCEPT OF INTELLECTUAL DISABILITIES THROUGHOUT HISTORY}

\author{
Milene Ferreira Bezerra (G-UEMS) \\ Paulo César Ribeiro Martins (UEMS/FIPAR)
}

\begin{abstract}
Resumo: O presente trabalho objetivou abordar as diferentes concepções a respeito da deficiência intelectual. Essa condição humana tem passado por vários conceitos, originando diversas terminologias, tais como: débeis, mongoloides, imbecis, retardados, deficientes mentais, portadores de necessidades especiais, portadores de deficiência e deficiência intelectual. Utilizou-se, como método de abordagem, o dedutivo. Como procedimento, usouse a pesquisa bibliográfica. Concluiu-se que em cada época a concepção vigente adequava-se ao conceito de homem e aos avanços da ciência daquele período. Na atualidade, especialistas, tanto da área da saúde como da área da educação, têm trabalhado para estabelecer conceitos que possibilitem a inclusão social e se distanciem o máximo possível da discriminação e do preconceito.
\end{abstract}

Palavras-chave: Pedagogia. Psicologia. História. Deficiência mental. Deficiência intelectual.

Abstract:This study aimed to address the different conceptions of intellectual disability. The human condition has gone through several concepts, leading to different terminologies, such as: weak, Mongoloids, stupid, retarded, mentally disabled people with special needs, disabled and mentally handicapped. It was used as a method of approach, the deductive. As a procedure, we used the literature review, concluded that each time a design suited to the prevailing concept of man and the advancement of science that period. Currently, experts from both the health area as the area of education have worked to establish concepts that enable social inclusion and distance themselves as much of the discrimination and prejudice.

Keywords: Pedagogy. Psychology. History. Mental deficiency. Intellectual disabilities.

\section{Introdução}

Os estudos sobre a deficiência intelectual começaram a tomar um caráter científico somente a partir do século XIX, época em que ela não era assim denominada. No entanto, pensou-se em estabelecer uma definição mais coesa para essa deficiência apenas no século seguinte, que, desde então, vem sendo aperfeiçoada. No retrospecto histórico, uma das mais antigas concepções é a de Doll, que, em 1941, estabelecia seis critérios para deficiência mental: 1. incompetência social, 2. devida a subnormalidade mental, 3. resultante de uma paralisação no desenvolvimento, 4. a qual prevalece na maturidade, 5. é de origem constitucional, 6. e é essencialmente incurável. (TELFORD; SAWREY, 1977). Em 1958, a associação Americana de Deficiência Mental (AAMR) procura definir o retardo mental, termo utilizado naquela época, como um funcionamento intelectual geral inferior à média, proveniente do período de desenvolvimento da criança e associado a prejuízos no comportamento adaptativo. (ASSUNPÇÃO JUNIOR; SPROVIERI, 2000). 
Já em 1970, Wert-Brecht cita a definição de Kraepelim, que denominava as crianças nessa condição como débeis mentais, afirmando que "[...] os débeis são pessoas em cujo cérebro não ocorrem muitas coisas" (ASSUNPÇÃO JUNIOR; SPROVIERI, 2000, p. 21). Um pouco mais tarde, Gindis (apud ASSUNPÇÃO JUNIOR; SPROVIERI, 2000) faz referências ao conceito de déficit mental, diferenciando os conceitos de déficit primário, considerando-o orgânico devido a sua associação a fatores biológicos endógenos e o déficit secundário, este referente às distorções das funções psicológica superiores, ocasionadas por fatores sociais.

Para Gindis (apud ASSUNPÇÃO JUNIOR; SPROVIERI, 2000), a pessoa que apresenta uma deficiência biológica automaticamente apresentará uma incapacidade de nível funcional, que acarretará num desempenho abaixo do esperado, de acordo com sua idade, sexo e grupamento social. Assim, haverá sempre limitações em suas atividades, tanto nos aspectos do funcionamento cognitivo, quanto em seu relacionamento com o mundo. Nesse sentido, a deficiência mental "não corresponde a uma única moléstia, mas, conforme menciona Krynski (apud ASSUNPÇÃO JUNIOR; SPROVIERI, 2000), trata-se de um complexo de síndromes que tem como única característica comum a insuficiência intelectual. Sobre a complexidade da deficiência intelectual, ainda no século passado, temos as importantes contribuições de Vygotski ${ }^{1}$.

\section{Deficiência intelectual segundo Vygotski}

Na primeira metade do século XX, uma das figuras que mais se destacaram nos estudos sobre as pessoas com deficiência, no contexto das sociedades russa e soviética, foi, sem dúvida, o psicólogo bielo-russo Lev Semenovich Vygotski (1896-1934). Seus trabalhos no campo das deficiências trouxeram contribuições importantes para se compreender as pessoas com algum tipo de desordem física ou mental. Na sua concepção, não havia distinção quanto ao desenvolvimento ontogenético das crianças com ou sem necessidades especiais e caberia à psicologia tentar entender o que caracterizava o desenvolvimento diferenciado entre as crianças "normais" e "anormais", destacando, em especial, as peculiaridades na ontogênese destas últimas. Assim, um dos objetivos de Vygotski era estabelecer uma pedagogia para as crianças com deficiência, enfatizando as mediações sociais, pois, do seu ponto de vista, “[...] seria necessário o estudo da dimensão social, já que considerava que o desenvolvimento psicológico do ser humano se daria pela sua vinculação ao grupo social”. (BEYER, 2006, p. 104).

Vygotski (1997) postulava que, inicialmente, o estudo das deficiências seguia uma abordagem quantitativa, baseada numa visão puramente clínica. Dessa forma, a deficiência era medida e quantificada em níveis, ou seja, havia apenas uma concepção aritmética da deficiência. $\mathrm{O}$ atraso mental, uma das expressões usadas pelo autor, era visto apenas como um fato clínico ou patológico, mas não como um processo. Os primeiros estudiosos pouco se importavam em caracterizá-lo e compreendê-lo em sua totalidade, sendo quase imperceptível a preocupação com os processos intervenientes no desenvolvimento das crianças débeis em relação às outras.

Para Vygotski (1997), primeiro se calculou, mediu e só depois se pensou em fazer um estudo qualitativo e descritivo dessa deficiência. Contrariando tal visão, propunha um novo enfoque para o estudo das pessoas com deficiência. Na perspectiva do autor, a ênfase não

\footnotetext{
${ }^{1} \mathrm{O}$ sobrenome de Vygotski tem sido traduzido do russo de várias formas. Neste trabalho, preservaremos a grafia de acordo com as referências usadas.
} 
deveria ser dada às limitações, mas às habilidades que essas crianças possuíssem. $\mathrm{O}$ objetivo principal, então, passaria a ser a definição das leis que proporcionavam o desenvolvimento mental das crianças atrasadas.

Naquela época, as crianças com deficiência eram denominadas como anormais, retardadas, imbecis, idiotas ou ainda como débeis. Essas nomenclaturas não eram vistas no sentido estritamente pejorativo, como atualmente, embora, sem dúvida alguma, já remetessem à ideia de crianças inferiores. Para Vygotski (1997), entretanto, essas crianças não eram menos desenvolvidas que as outras, consideradas "normais"; antes, elas possuíam suas peculiaridades, principalmente qualitativas, pelas quais se distinguiam, em seu desenvolvimento, das outras crianças.

Essa distinção, por sua vez, estava na estrutura orgânica e psicológica, e não em questões meramente quantitativas. A diferença estaria nas especificidades. Um exemplo disso seria o pensamento do "deficiente", que ocorreria de um modo distinto, com características e conteúdos muito próprios. Isso não significa, de modo algum, que ele venha a pensar mais ou menos em relação às demais pessoas. $\mathrm{O}$ autor supracitado acreditava também que nenhuma teoria ou prática seria possível tomando como ponto de partida o negativo. Segundo Vygotski (1997, p. 13), “[...] ninguma teoría es posible si parte exclusivamente de premisas negativas, así como no es posible práctica educativa alguna construida sobre la base de principios y definiciones puramente negativos[...]"2. Na mesma direção, defendia ainda que todo conhecimento científico precisaria de uma base filosófica e metodológica.

$\mathrm{Na}$ perspectiva vygotskiana, a compensação orgânica da deficiência defendida na época partia de um pensamento ingênuo, pois esta não aconteceria automaticamente, mas era algo sociopsicológico. O indivíduo precisaria se reestruturar em seu meio social e, para isso, deveria ser estimulado e orientado por pedagogos e psicólogos, juntamente com os recursos oferecidos culturalmente. A deficiência deveria ser vista em relação à personalidade e ao corpo todo, pois, nessa concepção, a personalidade se reestruturaria por meio do "defeito" e de sua relação com o meio social:

Sería erróneo suponer que el proceso de compensación siempre termina ineludiblemente en un logro, en un éxito, conduce siempre a la formación del talento a partir del defecto. Como cualquier proceso de superación y de lucha, también la compensación puede tener dos desenlaces extremos: la victoria y la derrota, entre los cuales se sitúan todos los grados posibles de transición de un polo a outro. El desenlace depende de muchas causas, pero en lo fundamental, de, sustitutivos, niveladores, que son generados por el defecto, y de la apertura de nuevos caminos de rodeo para el desarrollo. Un mundo de formas vías nuevas de desarrollo, ilimitadamente diversas, se abre ante la defectología. La línea defecto-compensación es precisamente la línea directriz del desarrollo del niño com el defecto de algún órgano o función. (VYGOTSKI, 1997, p. 16-17). ${ }^{3}$

\footnotetext{
2 “[...] nenhuma teoria é possível se parte exclusivamente de premissas negativas, assim como não é possível prática educativa alguma construída sobre a base de princípios e definições puramente negativas [...].”

${ }^{3}$ Seria errôneo supor que o processo de compensação sempre termina indubitavelmente em uma conquista, em um êxito, conduzindo sempre à formação do talento a partir da deficiência. Como qualquer processo de superação e de luta, a compensação também pode ter dois desfechos extremos: a vitória e a derrota, entre as quais situam-se todos os graus possíveis de transição de um pólo a outro. O desfecho depende de muitas causas, mas, fundamentalmente, da correlação entre o grau da insuficiência e a riqueza compensatória restante. Mas, seja qual for o desenlace que se espere do processo de compensação, sempre e em todas as circunstâncias o desenvolvimento agravado por um defeito constitui processo (orgânico e psicológico) de criação e recriação da personalidade da criança sobre a base da reorganização de todas as funções de adaptação, da formação de novos processos-sobreestruturados, substitutivos niveladores, que são gerados pelo defeito, e a abertura de novos
} 
A deficiência provocaria uma luxação social, a tal ponto que a pessoa se isolaria da sociedade, alterando suas antigas estruturas com os indivíduos e com o meio. Dessa maneira, tudo seria posto fora do lugar e o deficiente acabaria por ser um peso, ou alvo de atenção ilimitada, colocado em uma nova condição social, que projetaria seu desenvolvimento psicossocial para uma nova direção. Em outras palavras, seriam as consequências sociais que, primeiramente, levariam a pessoa a se sentir "anormal" e "deficiente", pois estas acentuariam e consolidariam o próprio defeito. Percebe-se então que as peculiaridades não estariam no biológico e sim no social. Como cita Vygotski (1997, p. 80-81) ${ }^{4}$, “[...] así, desde el punto de vista psicológico, el defecto físico provoca la pertubación de las formas sociales de conducta [...]. Absolutamente todas as peculiaridades psicológicas del niño deficiente tienen en su base um núcleo no biológico, sino social".

O conceito de deficiência intelectual, na concepção vygotskiana, seria o mais difícil e indefinido das deficiências no campo da pedagogia especial, pois suas causas poderiam estar relacionadas tanto as questões orgânicas ou hereditárias, quanto a fatores sociais. No caso da deficiência orgânica, Vygotski (1997, p. 202) aponta a existência de três categorias, classificando as crianças em:

[...] los idiotas, que no superan en su desarrollo el nivel de un niño de dos años, incapaces de utilizar herramientas e instrumentos y semi-incapaces de aprender el lenguaje; los imbéciles, que en su desarrollo no sobrepasan el nível de un niño de entre dos y siete años, capaces de aprender los tipos más simples de trabajo, pero incapaces de hacer cualquier trabajo en forma independiente; por último, los débelis, con el grado más leve de debilidad mental, capaces de un aprendizaje relativamente rico y de la asimilación de material, pero que manifiestan una actividad reducida de las funciones superiores, un ritmo de desarrollo lento, y conservan los rasgos del intelecto infantil (del niño de doce años) durante toda su vida y requieren una educación especil en las escuelas auxiliares. ${ }^{5}$

Segundo Vygotski, a coletividade infantil é muito importante, porque é a fonte, o meio nutritivo que proporciona uma forma completa para o desenvolvimento das funções psicológicas superiores nas crianças. Para o autor (1997, p. 214),

[...] en lo que respecta al desarrollo del niño, sólo durante o último período, y gracias a una serie de investigaciones, se logró determinar que también en este caso la organización y estructuración de las formas superiores de la actividade psíquica se

caminhos de desvio para o desenvolvimento. Um mundo de formas de caminhos novos de desenvolvimento ilimitadamente diverso abre-se diante da deficiência. A linha defeito-compensação é precisamente a linha diretriz do desenvolvimento da criança com o defeito de algum órgão ou função.

${ }^{4}$ Assim, desde o ponto de vista psicológico, o defeito físico provoca a perturbação das formas sociais de conduta [...]. Absolutamente todas as peculiaridades psicológicas da criança deficiente têm em sua base um núcleo não biológico, mas sim o social.

${ }^{5}$ [...] os idiotas, que não superam em seu desenvolvimento o nível de uma criança de dois anos, incapazes de utilizar ferramentas e instrumentos e semi-incapazes de aprender a linguagem; os imbecis, que, em seu desenvolvimento, não ultrapassam o nível de uma criança entre dois e sete anos, capazes de aprender os tipos mais simples de trabalho, porém incapazes de fazer qualquer trabalho de forma independente; por último, os débeis, com o grau mais leve de debilidade mental, capazes de um aprendizado relativamente rico e da assimilação de material, mas que manifestam uma atividade reduzida das funções superiores, um ritmo de desenvolvimento lento e conservam os traços do intelecto infantil (da criança de doze anos) durante toda sua vida e requerem uma educação especial nas escolas auxiliares. 
realizan en el proceso de desarrollo social del niño, en el proceso de su interrelación y colaboración con el médio social circundante. ${ }^{6}$

Na mesma linha de raciocínio, o autor salienta que o foco da intervenção pedagógica não devem ser os déficits primários, ou seja, os processos inferiores e elementares, como os problemas genéticos ou fisiológicos, mas sim os superiores, como o pensamento, a memória, e a linguagem racional. Estes, segundo a abordagem vigotskiana, são os processos mais propensos à ação pedagógica, visto que não dependem diretamente da constituição física da criança, mas sim da mediação da coletividade social

Dessa forma, é preciso combater a exclusão social, aproximando a criança com deficiência o máximo possível das outras, pois será esse convívio com as pessoas à sua volta que lhe dará condições de se reestruturar e redefinir seu papel social, desenvolvendo por completo suas funções psicossociais. Além disso, na condução desse processo, é necessário enfatizar sempre as habilidades da criança e não seus defeitos. (VYGOTSKI, 1997), como já vêm tentando fazer alguns educadores brasileiros na contemporaneidade, depois de uma longa história de lutas por melhorias no atendimento às necessidades dos deficientes intelectuais.

\section{História da deficiência intelectual no Brasil}

As primeiras preocupações em relação à educação das pessoas com deficiência, no Brasil, aparecem também no século XIX e ganham força ao longo do século XX, influenciadas por estudiosos europeus e norte-americanos, podendo ser divididas em dois períodos significativos, no âmbito da pesquisa histórica. O primeiro período estende-se de 1854 a 1956 e é considerado como um momento marcado pelas iniciativas oficiais e particulares isoladas, refletindo o interesse e a ação de alguns poucos educadores.

Este primeiro momento é definido pela instituição dos primeiros decretos e pelo aparecimento dos institutos especializados em cegueira e surdo-mudez do Império, ainda na segunda metade do século XIX, como evidencia a realização do primeiro Congresso de Instrução Pública em 1883. Esse congresso teve como objetivo a sugestão de um currículo específico para os cegos e surdos, bem como a formação de professores para atender esse público. Tais fatos levam, no começo do século XX, às primeiras leis da educação especializada profissionalizante e ao início das discussões científicas em torno do assunto. Também datam desse período as primeiras publicações técnico-científicas sobre o assunto e a preocupação com as crianças mentalmente atrasadas. (MAZZOTTA, 2001).

Nesse contexto, surgem ainda as primeiras instituições especializadas em atendimento aos deficientes intelectuais. Já na primeira metade do século XX, nota-se a existência de cerca de quarenta estabelecimentos de ensino regular público oferecendo algum tipo de atendimento escolar especial ao deficiente mental, além de quatro instituições especializadas, sendo uma pública e as demais particulares. Dentre essas, as que mais se destacaram foram o instituto Pestalozzi e a Associação de Pais e Amigos dos Excepcionais - APAE.

O instituto Pestalozzi foi o pioneiro a introduzir no Brasil a concepção ortopedagógica das escolas auxiliares europeias e a pedagogia social, do educador suíço Henrique Pestalozzi. A instituição, que existe até hoje, funcionava, a princípio, como um internato especializado,

\footnotetext{
${ }^{6}[. .$.$] no que diz respeito ao desenvolvimento da criança, somente durante o ultimo período, e graças a uma série$ de investigações, pôde se determinar que também neste caso a organização e estruturação das formas superiores da atividade psíquica se realizam no processo de desenvolvimento social da criança, no processo de sua interrelação e colaboração com o meio social circundante.
} 
em parceria com o poder público, e logo se expandiu para vários estados brasileiros, com o objetivo de proporcionar ao deficiente intelectual experiências com atividades rurais, artesanais, orientação pré-profissionalizante, além de promover, em nosso país, as instalações das primeiras oficinas pedagógicas nas áreas da marcenaria, cerâmica e outros trabalhos manuais simples. O instituto também foi o precursor na formação de profissionais especializados, organizando, em 1959, um curso intensivo de especialização de professores para ensinar os deficientes mentais. Com isso, dava-se início às primeiras classes especiais, supostamente visando ao desenvolvimento cognitivo das pessoas com deficiência intelectual. (MAZZOTTA, 2001).

Segundo Mazzotta (2001), a primeira APAE foi fundada no Brasil no ano de 1954, na cidade do Rio de Janeiro, contando com apoio, estímulo e orientação do casal norteameicano Beatrice e George Bemis, membros da National Association for Retarded Chidren (NARC). Essa associação acabou impulsionando as autoridades do executivo e legislativo a olharem pelos deficientes, propondo algumas leis em seu benefício. A APAE também se espalhou pelo país e atualmente tem como principal objetivo ser um centro de Atendimento Educacional Especializado (AEE).

Entre o final dos anos cinquenta e o início da década de sessenta, situa-se o segundo período, mais especificamente durante os anos de 1957 a 1993. Nessa data, começam a surgir as discussões políticas para uma educação mais sistematizada às pessoas com deficiência, denominada, nesse momento, como "educação de deficientes", "educação dos excepcionais" ou ainda "educação especial", aparecendo, finalmente, iniciativas oficiais de âmbito nacional. (MAZZOTTA, 2001).

Neste contexto, o autor supracitado, destaca ainda as primeiras campanhas especificamente voltadas a esse público, até então esquecido pela ampla sociedade. Uma dessas campanhas foi a instituída em 1960, liderada pela instituição Pestalozzi e também pela APAE, ambas do Rio de Janeiro. Essa campanha contou com o apoio do ministro da educação e cultura, sendo publicada no Diário Oficial da União, intitulada como Campanha Nacional de Educação e Reabilitação de Deficientes Mentais - CADEME.

A CADEME teve como propósito fomentar, em todo o território nacional, a educação, o treinamento, a reabilitação e a assistência educacional para as crianças "retardadas" e outros deficientes de qualquer idade ou sexo, pela seguinte maneira:

I- Cooperando técnica e financeiramente em todo território nacional, com entidades públicas e privadas que se ocupem das crianças retardadas e outros deficientes mentais.

II- Incentivando, pela forma de convênios, a formação professores e técnicos especializados na educação e reabilitação das crianças retardadas e outros deficientes mentais.

III- Incentivando, pela forma de convênios, a instituição de consultórios especializados, classes especiais, assistência domiciliar, direta ou por correspondência centros de pesquisa e aplicação, oficinas e granjas, internatos e semi-internatos, destinados à educação e reabilitação das crianças retardadas e outros deficientes mentais.

$I V$ - Estimulando a constituição de associações e sobretudo de funções educacionais destinadas às crianças retardadas e outros deficientes mentais.

$V$ - Estimulando a organização de cursos especiais, censos e pesquisas sobre as causas do mal e meios de combate. 


\begin{abstract}
VI- Incentivando, promovendo e auxiliando a publicação de estudos técnicos e de divulgação; a organização de congressos, conferências, seminários, exposições e reuniões destinadas a estudar e divulgar o assunto.

VII- Mantendo intercâmbio com instituições nacionais e estrangeiras ligadas ao problema.

VIII- Promovendo e auxiliando a integração dos deficientes mentais aos meios educacionais comuns e também em atividades comerciais, industriais, agrárias, científicas, artísticas e educativas.

Parágrafo $1^{\circ}$ - A CADEME não levará a efeito, sob qualquer forma, atividades puramente assistenciais, nem manterá ou dirigirá diretamente serviços, limitando-se á cooperação técnica e financeira.

Parágrafo $2^{\circ}$ - A CADEME dará prioridade às atividades de educação e reabilitação de crianças e adolescentes sem prejuízo, entretanto, dos outros deficientes mentais. (MAZZOTTA, 2000, p. 52).
\end{abstract}

A constituição da CADEME proporcionou um grande avanço legislativo no que diz respeito aos direitos das pessoas com deficiência como, por exemplo, a aprovação da lei $\mathrm{n}^{\mathrm{o}}$ 5.692/72, que previa, em seu artigo $9^{\circ}$, um tratamento especial aos excepcionais. Surgiram também várias diretrizes e bases legais para a educação de $1^{\circ}$ e $2^{\circ}$ graus, não cessando mais os avanços legislativos. Nesse cenário, em 1972, o Grupo-Tarefa de Educação Especial, formado pela portaria de 25 de maio de 1972 e gerenciado por Nise Pires, do Instituto Nacional de Estudos e Pesquisas - INEP, apresentou o relatório de Planejamento para o Grupo - Tarefa de Educação Especial do Ministério da Educação e Cultura do Brasil, propondo uma estruturação da educação especial no país, fato que resultou na criação de um órgão central no Ministério da Educação e Cultura para o atendimento aos excepcionais, o então denominado Centro Nacional de Educação Especial - CENESP. (MAZZOTTA, 2001).

Esse Centro Nacional de Educação tinha por objetivo, conforme definia seu regimento interno, impulsionar a difusão e a melhoria do atendimento às pessoas com deficiência em todo o território nacional. Entretanto, em 1990, com a reestruturação do Ministério da Educação, ele foi abolido e suas atribuições passaram a compor o Departamento de Educação Supletiva e Especial - DESE, que permanecia sob responsabilidade da Secretaria Nacional de Educação Básica - SENEB. Tais mudanças, porém, não tiveram muita longevidade, porque, em 1992, com uma nova reorganização dos Ministérios, criou-se a Secretaria de Educação Especial - SEESP, como um órgão específico do Ministério da Educação e Desporto. (MAZZOTTA, 2001).

Todos esses avanços na educação e nos direitos das pessoas com deficiência, como demonstra muito bem o aparecimento de órgãos governamentais de âmbito federal, acima mencionados, só foram conquistados, entretanto, pela forte participação dos pais e das próprias pessoas com deficiência, que, juntos, têm sido força importante para a efetivação de mudanças sociais e legislativas do país. De acordo com Mazzotta (2001, p. 64), "os grupos de pressão por eles organizados têm seu poder político caracterizado na obtenção de serviços e recursos especiais para grupos de deficientes, particularmente para os deficientes mentais e auditivos". Por essa via, suas necessidades têm chegado ao conhecimento social e governamental, assegurando-se, assim, que elas sejam sanadas e seus direitos respeitados. É a atuação decisiva desses movimentos que tem garantido inovações constantes na legislação brasileira, referentes a vários aspectos sociais, como reabilitação, seguridade, trabalho, transporte e educação das pessoas com deficiência. 


\section{Deficiência intelectual na contemporaneidade}

A definição atualmente utilizada para a deficiência intelectual, no meio científico, é a desenvolvida e regulamentada por documentos e associações internacionais, como o Diagnostic and Statistical Manual of Disordens - DSM-IV (Manual Diagnóstico e Estatístico de desordens Mentais) (2003) e a Associação Americana de Deficiência Mental (AAMR). (BALLONE, 2010). Tais documentos a definem como um estado de considerável redução da capacidade intelectual do indivíduo, que, nesse caso, apresenta-se abaixo da média, associada ainda a limitações em pelo menos dois aspectos do funcionamento adaptativo, como a comunicação, os cuidados pessoais, a saúde, as competências domésticas e escolares, as habilidades sociais, a utilização de recursos comunitários, a autonomia, segurança, lazer e ao trabalho. (BALLONE, 2010).

Logo, a deficiência intelectual está diretamente relacionada a limitações no funcionamento cognitivo, que, por consequência, ocasionam um comportamento abaixo do esperado para as crianças nessa condição, inclusive tendo-se em vista as características do seu meio social. Esse déficit intelectual é classificado pelo DSM-IV, e acordo com as recomendações da Organização Mundial de Saúde (OMS), em quatro níveis: o profundo, que engloba as crianças com um quociente de inteligência (QI) menor que 20; o severo, categoria que reúne os sujeitos com um QI entre 20 e 35; o moderado, com o índice de QI delimitado entre 36 e 51, e, por último, a categoria leve, na qual se situam as crianças com um quantitativo de QI mais alto, entre 52 e 67. As crianças que integram esse último nível costumam ser consideradas como "deficientes culturais", pois sua deficiência seria decorrente da ausência de estimulação cognitiva e ambiental, aproximando-se muito do coeficiente de inteligência considerado normal para a média da população, isto é, do QI igual a 70 (DSM-IV, 2003).

Já a AAMR (BALLONE, 2010), tentando superar essa visão ainda predominantemente quantitativa do DSM-IV, busca classificar a deficiência mental segundo níveis de apoio, que representam as mediações necessárias para que a pessoa supere suas limitações. Os apoios são definidos em: intermitente, necessário quando a criança não precisa de apoio constante, mas apenas em determinadas fases da sua vida, podendo ser um apoio de alta ou baixa intensidade; limitado, que é o apoio oferecido, em geral, num curto espaço de tempo; extenso, este caracterizado como um apoio diário, sem limitação de tempo, destinado às áreas e atividades em que a pessoa apresenta dificuldades acentuadas e ainda $\mathrm{o}$ generalizado, um apoio intenso e constante para subsidiar o indivíduo naquelas situações e atividades cotidianas em que seu desempenho está severamente prejudicado pela deficiência.

Vale ressaltar, após essa breve exposição do enfoque do DSM-IV e da AAMR, que embora existam nítidas diferenças de abordagem, ambos os documentos acabam chegando à mesma conclusão, ao afirmarem que uma criança só pode ser diagnosticada como deficiente intelectual caso demonstre, antes dos 18 anos de idade, um desempenho cognitivo abaixo do "padrão" considerado normal, associado a pelo menos duas daquelas dificuldades no funcionamento adaptativo, já listadas acima. Assim, a deficiência mental, tanto em um como em outro documento, deve ser definida a partir de testes psicométricos, capazes de "medir" a defasagem cognitiva do sujeito em relação às respostas comportamentais esperadas para sua idade e realidade sociocultural. (BALLONE, 2010).

Essas reflexões sobre a deficiência mental ao longo do tempo e na contemporaneidade 
fazem suscitar um aspecto muito relevante para o entendimento mais exato sobre tal condição humana. Trata-se, pois, do estudo das causas dessa deficiência, que, na atualidade, têm sido consideradas multifatoriais e ainda são objeto de diversas investigações científicas.

\section{Etiologia da deficiência intelectual}

Na década de 70, com o impulso dado pelas descobertas científicas e médicas, ganham força as especulações a respeito das possíveis causas da deficiência intelectual. Em 1977, Telford e Sawrey postulavam que a deficiência intelectual poderia ser ocasionada por vários fatores complexos, podendo assim ter uma causa diversificada e de difícil diagnóstico, envolvendo problemas genéticos e/ou questões de ordem ambiental e social. As alterações genéticas, mais raras, seriam ocasionadas por único gene dominante defeituoso, transmitido de geração em geração.. Nesse caso, os pais também seriam deficientes intelectuais. Nesse grupo, entretanto, geralmente não ocorreriam reproduções por falta de oportunidades ou devido à esterilidade (TELFORD; SAWREY, 1977). Além desse fator, a deficiência intelectual também poderia ocorrer por alterações cromossômicas numéricas ou estruturais, provocando, nessas circunstâncias, as Síndromes de Down, de Matin Bell e de Willians, ou ainda a esclerose tuberose etc. (BALLONE, 2010).

Nos países desenvolvidos, em quarenta e dois por cento dos casos não se encontram as origens da deficiência intelectual; em vinte e nove por cento constata-se a presença de alterações genéticas; dezenove por cento dos casos são provavelmente geneticamente determinados e dez por cento são decorrentes de fatores ambientais. (APAE, 2010). Pode-se ainda definir outras causas para essa deficiência, muito comuns nos períodos do pré-natal, do peri-natal e do pós-natal, em geral associadas a infecções, ingestão de álcool e outras drogas no período de gravidez, dificuldades na hora o parto, prematuridade, meningites, rubéolas, caxumba e traumas cranianos.

De acordo com Ballone (2010), os principais fatores de risco e causas pré natais, que podem sobrevir desde a concepção até o parto do bebê são a desnutrição materna, a má assistência na gestação, doenças infecciosas como rubéola, sífilis e toxoplasmose e a ingestão de tóxicos, drogas e cigarros, efeitos colaterais de medicações teratogênicas, além da poluição ambiental. Já os riscos periantos, que incidem desde o trabalho do parto até o $30^{\circ}$ dia de vida do recém-nascido, estão relacionados à má assistência do parto, provocando traumas, a falta de oxigenação cerebral ou a prematuridade e o baixo peso. Por último, dentre as causas e riscos do pós-natal, que se estende do $30^{\circ}$ dia de vida do bebê até o final de sua adolescência, encontram-se a desnutrição, a desidratação grave, a carência de estimulação global, as infecções, intoxicações exógenas (envenenamento), os acidentes e ainda a infestação por neurocisticircose. (BALLONE, 2010).

Todas essas causas podem ser identificadas pela observação sistemática do desenvolvimento da criança, realizada por uma equipe de profissionais, que terá condições de perceber os possíveis atrasos em seu desenvolvimento neuropsicomotor, como, por exemplo, a demora para firmar a cabeça, para sentar e andar, os atrasos no desenvolvimento linguístico, com limitações manifestas quanto à compreensão de normas e ordens, bem como as dificuldades surgidas durante o aprendizado escolar. Para tanto, recomenda-se que esses profissionais sejam assistentes sociais, médicos, pedagogos e psicólogos, que, juntos, observarão os aspectos sociais, culturais, biológicos, cognitivos e psicológicos da criança, definindo, com base nesse trabalho interdisciplinar, as melhores estratégias a serem tomadas 
em relação ao atendimento que essa criança deverá ter, inclusive com a participação constante da família. (BALLONE, 2010).

Por fim, vale mencionar que a deficiência intelectual pode ser prevenida, eliminandose ou minimizando-se alguns fatores de risco. Uma dessas medidas preventivas seria justamente a orientação aos familiares, com o esclarecimento sobre essa deficiência e sua etiologia. Nesse sentido, famílias com histórico de deficiência, casais com parentesco consanguíneo e mulheres com idades mais avançadas deveriam ser orientadas a procurar acompanhamento médico, antes de decidirem ter filhos.

O acompanhamento pré-natal adequado também pode detectar problemas ou infecções maternas, que podem ser tratadas já nessa fase, antes mesmo de atingir o feto. Além disso, uma boa alimentação e atividades físicas apropriadas contribuem para gestações e bebês saudáveis. No pós-natal, algumas medidas profiláticas devem ser observadas, tais como não deixar de fazer o teste do pezinho após o nascimento do bebê, garantir a aplicação de todas as vacinas, proporcionar alimentação adequada à criança e um ambiente familiar saudável, evitando-se acidentes e traumas físicos, ao mesmo tempo em que propicia ao bebê estímulos cognitivos e sociais adequados a cada fase. (APAE, 2010). Todos estes cuidados são, certamente, muito importantes para evitar qualquer tipo de deficiência e, sobretudo, para proporcionar uma vida digna a todas as crianças, independentemente se elas apresentam ou não deficiências intelectuais.

\section{Considerações finais}

Ao longo desse breve recorte histórico, observou-se que o avanço dos estudos sobre as deficiências, sobretudo a deficiência intelectual, teve maior relevância a partir do final do século XIX, continuando com mais vigor no início do século XX. Dentre os estudiosos do assunto, destacou-se a figura notória de Vygotski que apresenta um olhar positivo sobre as deficiências humanas, tirando o foco das questões biológicas e das dificuldades que as pessoas deficientes apresentam, para enfatizar, em contrapartida, os aspectos sociais, responsáveis pela inclusão ou exclusão do deficiente intelectual à vida em coletividade e, consequentemente, pelo sucesso ou pelo fracasso de seu desenvolvimento cognitivo. Com essa perspectiva, Vigotski é um dos poucos estudiosos que não priorizam excessivamente os aspectos médicos ou orgânicos da deficiência, valorizando o potencial de cada ser humano, em vez de se deter apenas nas limitações das pessoas. Assim, o autor proporciona, em termos psicopedadógicos, uma visão moderna para a compreensão do fenômeno deficiência, com o intuito de priorizar a emergência do potencial de cada indivíduo e a sua inclusão na coletividade, na esfera mais ampla da vida social.

Constatou-se também que, no Brasil, a história da educação das pessoas com deficiência intelectual teve uma longa jornada, envolvendo vários movimentos ligados à educação, inclusive governamentais, que lutavam por um tratamento mais adequado para as pessoas com deficiências. Na contemporaneidade, também não se desprezam as contribuições dos profissionais da saúde, que, por meio de sua atuação em sociedades internacionais como a Organização Mundial da Saúde, muito têm contribuído para garantir um assistência mais justa aos indivíduos nessa condição. Esses mesmos profissionais têm ainda colaborado significativamente com o avanço do conhecimento na área em questão, ajudando na organização e divulgação de intervenções profiláticas, a fim de tentar prevenir o aumento do número de casos de pessoas com deficiências. 
Hoje, busca-se, cada vez mais, antecipar a estimulação precoce das crianças com e sem deficiência intelectual, garantindo-se maiores oportunidades para seu desenvolvimento cognitivo, como ocorre durante Educação Infantil. Por outro ângulo, a partir de campanhas governamentais e dos esforços de pesquisadores, tanto da área da Educação como das Ciências Humanas e das Ciências da Saúde, o trabalho com deficientes intelectuais tem pautado, finalmente, pela sua ampla inclusão social e pelo combate explícito à discriminação e ao preconceito. Nesse sentido, a sociedade parece caminhar para o reconhecimento de que essas pessoas, assim como as demais, possuem o direito de crescerem e se desenvolverem plenamente, usufruindo de sua cidadania e contribuindo para a constituição de um mundo mais digno, ético e solidário.

\section{Referências}

APAE de São Paulo. O que é deficiência intelectual?. Disponível em:

$<\mathrm{http}$ ://www.apaesp.org.br/DeficienciaIntelectualHome.aspx>. Acesso em: 05 jun. 2010.

ASSUMPÇÃO JUNIOR. F. B.; SPROVIERI, M. H. Introdução ao estudo da deficiência mental. São Paulo: Memnan, 2000.

BALlONE, G. J. Deficiência mental. Disponível em:

$<$ http://gballone.sites.uol.com.br/infantil/dm1.html>. Acesso em: 21 abr. 2010.

BEYER, Hugo Otto. Inclusão e avaliação na escola: de alunos com necessidades especiais. 2. ed. Porto Alegre: Mediação, 2006.

CARVALHO, Erenice Natália Soares de; MACIEL, Diva Moraes de Albuquerque. Nova concepção de deficiência mental segundo a American Association on Mental Retardation AAMR: sistema 2002. Temas em Psicologia: Sociedade Brasileira de Psicologia, Ribeirão Preto, vol.11, n. 2, p. 147 - 156, 2003. Disponível: em <htpp:

//WWW.sbponline.org.br/revista2/vol1n2/art07_t.htm> Acesso em: 06 jun. 2010.

MANUAL diagnóstico e estatístico de transtornos mentais (DSM-IV-TR). 4. ed. Tradução Cláudio Dornelles. Porto Alegre: Artmed, 2003.

MAZZOTTA, José Silveira Marcos. Educação especial no Brasil: história e políticas públicas. 3 ed. São Paulo: Cortez, 2001.

TELFORD, W. Charles; SAWREY, M. James. O indivíduo excepcional. 5. ed. Nova Jersey: Livros Técnicos e Científicos, 1977.

VYGOTSKI, Lev Seminóvic. Obras Escogidas. Fundamentos de Defectología. Madrid: Visor, 1997. Tomo V. 